\title{
The Life Skills Assessment Scale: the construction and validation of a new comprehensive scale for measuring Life Skills.
}

\author{
Dr. R. Subasree, Dr. A. Radhakrishnan Nair \\ Assistant Professor, School of Counselling Rajiv Gandhi National Institute of Youth Development \\ Sriperumbudur, Tamil Nadu, 600042. \\ Officer on Special Duty to MOA. Labour and Employment, Govt. of India.
}

\begin{abstract}
The purpose of this study was to develop a valid, reliable scale to measure life skills. The first phase involved the conceptualization and operationalization of life skills based on the review and identifies the research gaps. Similar questionnaires, scales were reviewed, based on that the items were framed for the tool. In the second phase, Face and content validity were assessed by a panel of experts, data collection $(N=890)$ was carried out extensively to establish reliability and validity for the Life Skills Assessment Scale. Using Cronbach's coefficient alpha, test retest, split half reliability methods the internal consistency was assessed for the tool. After item analysis and construct validity assessment, the test items showing weak indicators were eliminated in a stepwise fashion until the reliability coefficient peaked. However, highest reliability was already obtained without eliminating items. The final summated scale of 100 indicators had a Cronbach's alpha coefficient of .84. The psychometric properties were established adopting standard procedure.
\end{abstract}

Key words: Life Skills, Assessment Scale.

\section{Introduction}

Life skill refers to a positive behaviour that encompasses a mix of knowledge, behaviour, attitudes and values and designates the possession of certain skills and know-how to do something positively, or reach an aim. The strength of the positive behaviour depends upon the depth of the skills acquired by the individual. The OECD (Organisation for Economic Cooperation and Development) has adopted a more generic definition of life skills in the context of the DeSeCo (Definition and Selection of Competency) project (Rychaen and Salganik 2001). It defines life skills on three general criteria, namely that

a) key competencies contribute to an overall successful life and a well-functioning society,

b) they are instrumental to meeting important challenges in a wide spectrum of relevant contexts, and finally,

c) they are relevant to all individuals.

These key competencies are:

a) functioning in socially heterogeneous groups,

b) acting autonomously and

c) using tools interactively.

Competency is more than just knowledge and skills. It involves the ability to meet complex demands, by drawing on and mobilising psychosocial resources (including skills and attitudes) in a particular context. For example, the ability to communicate effectively is a competency that may draw on an individual's knowledge of language, practical IT skills and attitudes towards those with whom he or she is communicating. Individuals need a wide range of competencies in order to face the complex challenges of today's world. Through the DeSeCo Project, the OECD has collaborated with a wide range of scholars, experts and institutions to identify a small set of key competencies, rooted in a theoretical understanding of how such competencies are defined. Each key competency must:

- Contribute to valued outcomes for societies and individuals;

- Help individuals to meet important demands in a wide variety of contexts; and

- Be important not just for specialists but for all individuals.

The generic understanding of life skills from the dual angle of personal fulfilment and realisation of social responsibility includes both empowerment and self-fulfilment and the capacity to be a part of a heterogeneous group and strive for common goals. They can also imply success in personal and professional life. Seen from a social point of view they can mean cohesion, happiness, well being and good functioning of a group, as well as success in relating to others and living together. The idea of success is not only the accomplishment of a happy working life, but also the creation of a self-fulfilling life outside the world of work and wealth creation. (Ouane 2002). Life skills are developed as a result of a constructive processing of information, impressions, encounters and experiences, - both individual and social - that are a part of one's daily life and work and the rapid changes that occur in the course of one's life. Life skills are essentially those 
abilities that help promoting mental well being and competence in young people as they face the realities of life. In general, Life skills education as skills based approach is mainly lies on five important theoretical frameworks:

\section{Social Cognitive Theory:}

First, is the Social Cognitive Theory by Bandura,(1986). The Social Learning Theory of Miller and Dollard (1941) provides a platform for the later work by Bandura in 1977. The key concepts in the earlier theory were imitation and modeling. In 1977, Bandura published his seminal work, "Social Learning Theory", which incorporated cognitive elements into the theory. Later in 1986, Bandura contributed with a comprehensive framework and renamed it as Social Cognitive Theory. (SCT -Baranowski, Perry, \& Parcel, 1997). Among the crucial personal factors are: a person's ability to symbolize behavior, to learn by observing others, to have confidence in performing a behavior, to self-regulate behavior, and to reflect on and analyze experience (Bandura, 1986).

\section{Problem-Behavior Theory:}

Richard Jessor, developed this theory, which looks at adolescent behaviour as a product of complex interactions. It focuses on three areas: the personality, the perceived environmental system and the behaviours. Personality is defined as "values, expectations, beliefs, attitudes and orientations towards self and society." The environmental system consists of parental and societal (including friends) expectation and the behavioural system describe a set of socially unacceptable behaviours. Within this interactive system some variables act as controls and some variable trigger problem behaviours and hence are called as instigators. This theoretical framework is situated within the traditional approaches and its utility in life skills education is limited to working with special population or populations presenting non adaptive behaviours.

Social Influence Theory:

McGuire (1964, 1968) was the first person to use the term "psychological inoculation". Social influence theory recognizes the importance that social processes have on persons in making their choices as well as living particular kinds of life styles. Therefore, the key task for a life skill intervention within this theoretical framework is to prevent the maladaptive social influences. Here the term, "peers pressure" is significant. Social influence also includes negative role models, media as a social influence and messages from other contexts like school, family and neighbourhoods etc. (Evans, 1998) The key contribution of this approach is in anticipating such influences and teaching children and adolescents ways and means to resist social influences that engender risk behaviours, hence the term "psychological inoculation". This approach was first used by Evans (1976; et al, 1978) in smoking prevention programs, and is now usually referred to as "peer resistance education". Evans successfully combines the theory on child and adolescent growth in developmental psychology with the social influence theory for successful interventions. These programs are for a specific sample, with specific objectives and relate to life skills in as much as the life skills are related to assertiveness, social skills and peer resistance, self esteem and communication skills. They include knowledge, attitude and practices relating to these specific skills, target population and training objectives.

\section{Cognitive Problem Solving:}

According to a review report by Mangrulkar et al,( 2003), cognitively based competence-building model of primary prevention theorizes that teaching Interpersonal Cognitive Problem Solving (ICPS) skills to children at a young age can reduce and prevent negative inhibited and impulsive behaviours. It has been known through various researches that, right from the preschool and early school years, children show difficulties in interpersonal skills and other problem solving thinking skills concurrently. This is in contrast with children who express enhanced positive social behaviours and enhanced thinking skills. It has also been found that children who show difficulties in interpersonal skills display high risk behaviours. Cognitive problem solving theory implies teaching cognitive strategies to resolve interpersonal problems and improve interpersonal skills. This includes finding alternative solutions, recognizing the consequences of risk behaviours etc. The assumption of this theoretical approach is that training in the early years reduces the risk behaviours consequently reducing the possibility of a negative outcome. This theory uses methodologies like visualizing alternatives, storytelling, role plays etc. Some research (Shure and Spivack,1980) has reported that children are better able to cope with frustration, control of impulses and manage delayed need gratification.

This competence based theoretical view underlies the notations of "emotional competence" (Denham, 2006; Saarni, 2006). It is especially useful in early childhood, however, can be utilized as a framework even in adolescence.

Theory of Multiple Intelligence: 
Gardner's Theory of multiple intelligence challenges the early notion of intelligence as a purely verbal, cognitive construct. According to Gardner's theory, there exist eight kinds of intelligences, although in a person one or two kinds may predominate. Multiple intelligence includes abilities like linguistic, logical/mathematical, musical, spatial, bodily/kinaesthetic, naturalist, interpersonal and intrapersonal intelligences. The theory of multiple intelligence is important and departs from the way education and pedagogy as well as training is conceptualized and practiced leaving out vast areas of human psyche untouched and unexplored.

The life skills approach also seeks to fill this gap in modern education and it creates an awareness of one's environment, of social dynamics and of the roles one play and wants to play. It requires individuals to be empowered to manage their lives in meaningful and responsible ways by exercising control over their living and working conditions. Individuals must act autonomously in order to participate effectively in the development of society and to function well in different spheres of life including the workplace, family life and social life. In order to face the challenges in everyday life, it is imperative to build the capacities of the adolescents and young people to cope up with various pressures and demands. 'Capacity building' here refers to the foster assimilating knowledge, enhance skills, upgrade the competence to plan and execute tasks and further engineer their characteristic traits. This is done through providing support in a guided learning situation, thereby achieving effectiveness in a range of activities.

To Sum up the life skills are vital for Holistic development of the individual, whether it can be called as Intelligence, Personality, Capacity building and researchers refer a mixture of names for life skills like Social Competence, Practical intelligence, Emotional intelligence or Psychosocial wellbeing. Whatever may the term be, the whole meaning is to enhance Life Skills and to improve "the abilities individuals can learn that will help them to be successful in living a productive and satisfying life ( Hendricks,1996). As Miller (1976) defined leadership life skills development as self-assessed and organization specific "development of life skills necessary to perform leadership functions in real life." His research contribution denotes that Life skills are the key components and indicators on youth leadership life skills development. Holistically, Powell (1985) defined life skills as the life-coping life skills consonant with the developmental tasks of the basic human development processes, namely those life skills necessary to perform the tasks for a given age and sex in the following areas of human development: psychosocial, physical-sexual, vocational, cognitive, moral, ego, and emotional. Enhancing Life Skills enables oneself to adapt to situations and people and helps to lead a healthy and positive life.

\section{Need for a Life Skills Assessment Scale}

Although, there is adequate theoretical frame-work on life skills education, very few scientific tools for life skills assessment have been devised by various behavioural scientists. Conceptual review also indicated the lack of a such a scale and therefore, the need for construction of a systematic assessment tool. Further, for early interventional purposes, the need for a multi-dimensional life skills assessment tool was required while working with large number of adolescents. To identify the problems while providing life skills interventional services, it is highly imperative for baseline assessment of life skills the participants possess and also to evaluate the effective of post intervention provided services. It is in this backdrop of vital significance the requirement RGNIYD poised to undertake a action-research project to prepare a life skills assessment scale based on the ten core life skills in consonance with the frame-work suggested by the World Health Organisation.

Conceptually, this tool is based on the WHO framework of 10 core Life Skills.

The most important and basic ten generic life skills are outlined below:

\section{Self Awareness}

Self awareness is the awareness about oneself (self consciousness). It includes one's recognition of themselves, one's character, one's strengths and weaknesses, desires and dislikes. This helps the adolescent to understand his/her self worth and builds his/her confidence to face life boldly. It also enables one to identify ones weaknesses or negative personality traits and consequently improve oneself. Some of the self related terms are used as synonyms are self image, Self concept and Self esteem.

\section{Empathy}

Empathy is one's ability to understand and accept different kinds of people around them who are different in many respects. Empathy is our mental capacity to accept without emotional disturbances, of people in distress as if we are in such a distress situation. It includes understanding one's feelings as well as providing emotional support for that person. Empathy also help to encourage nurturing behaviour towards people in need of care and assistance or tolerance. It helps an adolescent to understand and accept others who are different from him/her.

\section{Effective communication}

Effective Communication is an efficient tool for the establishment and maintenance of good social and working 
relationships with people. It is a way of reaching others by transmitting ideas, facts, thoughts, feelings and values. One's ability to express himself/herself both verbally, in ways that are appropriate to our cultures and situations. It enables an adolescent to express his opinions, desires and fears clearly by using both verbal communication and non-verbal expressions. It also trains the adolescent to ask for advice and help from others in times of need.

\section{Inter Personal Relationship}

Inter Personal Relations are known as survival skills which is very imperative for establishing and maintaining social relationships. Interpersonal skill is to initiate and maintain positive relationship with other individuals and de-link unconstructive relationship, with minimum disturbances to both.

Relating with others is an important life skill and one of the most important forms of human intelligence and called as people skill, which provides warmth, caring, support and collaboration that give life its excitement and potential for joy and personal fulfillment. It teaches an adolescent to relate to other people in a positive manner. It also helps him/her to develop the ability to end relationships constructively.

\section{Creative thinking}

Creativity is the ability to generate innovative ideas and manifest them from thought into reality. The process involves original thinking and then producing. Creativity is typically used to refer to the act of producing new ideas, approaches or actions. Creativity is the ability to produce work that is both novel (original and unexpected) and appropriate (useful or meets tasks constraints). It helps an adolescent to respond in a flexible manner to various challenges of life. It enables him/her to explore available possible alternatives and to assess their consequences. This skill helps in both problem solving and decision-making.

\section{Critical Thinking}

Critical thinking is defined as logical thinking and reasoning including skills such as comparison and classification; Critical Thinking is that mode of thinking about any subject, content or problem in which the thinker improves the quality of her or his thinking by skillfully taking change of the structures inherent in thinking and imposing intellectual standards upon them. A skill that enables an adolescent to analyze information and experiences objectively. It also helps to recognize factors like family values, peer and media pressures that influence attitudes and behaviour.

\section{Decision-making}

Decision Making is the ability to choose the best amongst the various alternatives or options in many life situations. The skill to analysis and weigh the pros and cons of alternatives and accepting responsibility for the consequences of the decision with confidence. It enables an adolescent to make constructive decisions about one's life like choice of a career or marriage partner, type and quantity of dietary intake etc. It teaches that, decision be made only after assessing different options and their effects.

\section{Problem solving}

Problem Solving skills enable us to deal constructively with problem that arises in our live.This skill is helpful to settle an issue, solve a problem or to resolve a conflict. It eables the person to get out of the uncomfortable situation and accomplish one's need without using anger, coercion, defiance, aggressive behaviour or force. Scientifically, problem solving is a process to bring an opportunity for a positive act. It helps an adolescent to solve his/her problems by using creative and critical thinking.

\section{Coping with emotions}

Coping with emotions helps the individual to understand feelings of them and others. This skill helps to know that it is normal to have strong feelings and that feelings are neither positive nor negative. Accepting feelings is the first step towards learning to have more control over them. Life skills enable the individual to learn healthy, positive and safe ways to express these feelings. It enables an adolescent to recognize emotions in oneself and others, to realize its effects on behavior and to respond to emotions appropriately. Uncontrolled emotions like excessive sorrow and anger are referred to in this dimension.

\section{Coping with Stress}

Coping with stress enable the individual to recognize the sources of stress, understanding its effects and relax without making the situation worse. This skill provides the strength to face positive or negative stressful situations. Deal with accompanying emotions and look for solutions that are most beneficial. Coping with stress. An adolescent to recognize sources of stress and its effects. It also discusses methods to control 
stress and to overcome it.

\section{Description of the Life Skills Assessment Scale}

Life Skills can be acquired and enhanced, to bring in personal success in all spheres and for leading quality and productive life. Life Skills are potential of being observed through measurement and a visible change in behaviour could be overtly seen through life skills enhancement training. Recognising the conceptual frame-work of WHO, the Life Skills Assessment Scale was constructed to assess the levels of life skills among Indian adolescents.

The multi-dimensional Life Skills Assessment Scale consists of 100 items (one hundred only) in the form of statements in-built with a 5-point scale for the respondent to check the appropriate response which is most descriptive of him/her viz., Always true of me, Very true of me, Sometimes true of me, Occasionally true of me and Not at all true of me.

It has both positive and negative items. The 100 test items have been arranged in such a fashion that the one test item pertaining to each dimension being measured are arranged one after the other ie., the test items under the first dimension are arranged in the order of $1^{\text {st }}, 11^{\text {th }}, 21^{\text {st }}, 31^{\text {st }} \ldots$ item sequence. This approach was adopted with a view to reduce the halo effect and the logical errors and also to relieve the respondent from monotony. Precise care has been exercised to ensure that the double barrelled statements are avoided.

The added advantage is that the tool could be self administrated or could be utilised in a group situation.

The Life Skills Assessment Scale (LSAS) measures ten (10) dimensions of Life Skills as indicated below:

Table1: Dimensions of Life Skills and Number of Items

\begin{tabular}{|l|l|l|}
\hline S. No & Dimensions of Life Skills & No. of Items \\
\hline 1 & Self awareness & 11 \\
\hline 2 & Empathy & 11 \\
\hline 3 & Effective Communication & 09 \\
\hline 4 & Interpersonal Relationships & 11 \\
\hline 5 & Creative Thinking & 08 \\
\hline 6 & Critical Thinking & 11 \\
\hline 7 & Decision Making & 11 \\
\hline 8 & Problem Solving & 09 \\
\hline 9 & Coping With Emotions & 11 \\
\hline 10 & Coping with stress & 08 \\
\hline
\end{tabular}

The scores obtained under each dimension represent the level of life skills in the respective domain and summation of all the score obtained under each of the 10 dimensions would evolve as a global score for life skills.

\section{Standardisation}

During the workshop held with the National Adolescent Resource Team (NART) held during April,2008, the experts, academicians and professionals working in the field of Life Skills Education and Training suggested that Rajiv Gandhi National Institute of Youth Development (RGNIYD), an Institution deemed to be University under the section 3 of the UGC Act, 1956 should take up the task of constructing an Assessment Scale on Life Skill due to the fact that RGNIYD has a full-fledged School of Life Skills Education. Based on this recommendation, the School of Life Skills Education initiated a research project on Construction of an Assessment Scale for Life Skills from July 2009. Careful literature review was done through which about 500 studies on the subject of life skills education, assessment and training were collected from various sources.

These studies included conceptual and empirical studies conducted on the ten core life Skills till 2009. Each member of the research team visited various universities in India for collecting relevant material, studies and related tools. Members of the team also established contact with researchers and academicians in the specified area. Based on reviews, the list of various life skills referred to in various studies were delineated for the purpose of deciding the areas to be covered under the 10 core life skills and also to pool the test items pertaining to each dimension.

The type of items were carefully selected and built into each dimension so as to ensure that these terminologies are being frequently used by a cross-section of professionals' viz., Psychologists, Sociologists, Management Professionals as well as professionals engaged the field of Life Skills Training.

Principles such as relevance, clarity of test items, were strictly adhered to in order to establish congruence with the research background considering the face validity of the test items judged by the research team in the first place.

The appropriateness of language and the level of difficulty of the test items were reduced to suit the needs of the larger section of the rural adolescents. Though some of the skills are inter-linked, care was exercised to include the test items closely related to each of the dimensions being measured and also to avoid 
duplication of test items in the other dimensions. Following a series of brain-storming exercises, large pools of items assimilated were distributed under each dimension by a group of eminent experts.

During the NART Meeting held in April 2010, the expert team consisting of various professionals and experts hailing from disciplines such as Psychology, Sociology, Social Work, Education, Management, and Practitioners in Life Skills Education scrutinised each of the test item and established the Face and Content validities of the Scale. Based on the suggestions of the experts, certain test items were modified and a few were eliminated. The collective consensus was obtained on the draft scale and later a few test items were rephrased. The tool thus framed was ready to pilot testing.

A focussed group discussion was held with the key stakeholders $(\mathrm{N}=30$, adolescents) to obtain a feedback on the adequacy of the scale and to judge the appropriateness of the test items under each dimension. Further, to corroborate this effort, another group of students $(\mathrm{N}=36)$ were requested to write and share the meaning of each statement included as an item. This was done to ensure unambiguity of test items. Finally, the research team based on a series of scientific procedures, decided to reduce items from 121 into 100. This was also done through consultation with experts.

For the purpose of standardizing the LSAS, a total of 890 samples hailing from various backgrounds such as rural, urban, tribal, school and colleges from across the country. The pilot test was carried out at various levels with the help of research scholars, research assistants and psychologists. Table No-1 provides a demographic profile of these groups. The primary inclusion criteria for sample selection were adolescents of age ranging 12years to 19years and students familiar with English language.

Table-1 : Background Characteristics of the sample ( $N=890)$

\begin{tabular}{|c|c|c|}
\hline Variable & Frequency & Percentage \\
\hline Age & 32 & 3.6 \\
\hline 13 & 180 & 20.1 \\
\hline 14 & 302 & 33.8 \\
\hline 15 & 181 & 20.2 \\
\hline 16 & 90 & 10.1 \\
\hline 17 & 30 & 3.4 \\
\hline 18 & 27 & 3.0 \\
\hline 19 & 48 & 5.4 \\
\hline $\begin{array}{ll}\text { Gender } & \text { Male }\end{array}$ & 530 & 59.4 \\
\hline Female & 360 & 40.6 \\
\hline Type of Family $\quad$ Joint & 211 & 23.7 \\
\hline Nuclear & 679 & 76.3 \\
\hline Order of Birth $\quad 1^{\text {st }}$ Born & 257 & 28.8 \\
\hline $2^{\text {nd }}$ Born & 441 & 49.4 \\
\hline Later Born & 192 & 21.8 \\
\hline
\end{tabular}

\section{Reliability}

Extensive data were collected to establish reliability and validity for the Life Skills Assessment Scale. Using Cronbach's coefficient alpha, test retest, split half reliability methods the internal consistency was assessed for the tool. Using Cronbach's coefficient alpha, reliability was assessed on the scale remaining after item analysis and construct validity assessment. The test items showing weak indicators were eliminated in a stepwise fashion until the reliability coefficient peaked. However, highest reliability was already obtained without eliminating items. The final summated scale of 100 indicators had a Cronbach's alpha coefficient of .84 .

Table-2: - indicates the reliability Coefficients for LSAS

\begin{tabular}{|l|l|}
\hline Type of Coefficient & Reliability \\
\hline Split-half & 0.82 \\
\hline Test-Retest & 0.91 \\
\hline Cronbach's Alpha & 0.84 \\
\hline
\end{tabular}

Table-3: Reliability Coefficients dimension wise for Life Skills Assessment Scale

\begin{tabular}{|l|l|l|}
\hline NO & DIMENSION & RELIABILITY \\
\hline 1 & Self Awareness & .31 \\
\hline 2 & Empathy & .36 \\
\hline 3 & Effective Communication & .39 \\
\hline 4 & Interpersonal Relationship & .33 \\
\hline 5 & Creative Thinking & .44 \\
\hline 6 & Critical Thinking & .56 \\
\hline 7 & Decision Making & .40 \\
\hline 8 & Problem Solving & .47 \\
\hline 9 & Coping with Emotion & .42 \\
\hline 10 & Coping with Stress & .38 \\
\hline
\end{tabular}


The above tables indicate that the Life Skills Assessment Scale is highly reliable and scores are fairly consistent over the period of time in line with the research by Pershad and Wig 1978.

Validity:

An extensive exercise was done to establish face and content validity of the Life Skills Assessment in the initial stage of the tool construction. The item discriminant analysis was carried out and the scale was potential of discriminating high scorer and low scorer on the relevant scales. The criterion validity was established by conducting structured interview with teachers and significant others of the students (sample of the study, N=30) on high and low scorers in Life Skills. Further the judgement of each student's score by the teachers and his/her actual score were taken into account and those items are retained since it measures what is actually exhibited. The correlation between percentage obtained by each student in each skill and the teachers' judgement on each student were calculated which indicated $89 \%$ concurrence.

The Life Skills Assessment Scale is a self administration Scale. This Scale can be administered to a group or to an individual. The procedure for the administration is given below.

The individual are given instructions to be seated comfortably and would be provided instructions about the assessment as per the details given below:

"This questionnaire assesses the level of life skills in the adolescent population. Below are some statements. They try to find out your way in life and perspectives about living. Kindly go through the statements carefully and answer according to what is true for you. There are no right or wrong answers. This will be used only for research purpose and it will be kept confidential."

The test administrator requires certain precautions to be taken viz., making sure that the individual has understood the directions, respondent not to omit any statements and answer all the statements.

\section{Scoring:}

The Scoring for the Life Skills Assessment Scale is based on the five point scale ranging from Always true of me to Not at all true of me.

\section{Norms and Interpretations:}

The Norms of the Life Skills Scale was established using Mean and SD of the scores obtained in respect of 890 respondents. The Mean and SD was taken as cut off score to arrive at the Norms.

Table-4: The following Mean and Standard Deviation (SD) values obtained based on testing 890 school and college students:

\begin{tabular}{|l|l|l|l|}
\hline S.No & Dimensions & Mean & SD \\
\hline 1 & Self awareness & 38.84 & 4.91 \\
\hline 2 & Empathy & 40.77 & 5.15 \\
\hline 3 & Effective Communication & 30.31 & 4.77 \\
\hline 4 & Interpersonal Relationships & 39.43 & 4.89 \\
\hline 5 & Creative Thinking & 29.22 & 4.37 \\
\hline 6 & Critical Thinking & 40.99 & 5.56 \\
\hline 7 & Decision Making & 38.34 & 5.05 \\
\hline 8 & Problem Solving & 35.04 & 4.77 \\
\hline 9 & Coping With Emotions & 36.51 & 5.24 \\
\hline 10 & Coping with stress & 25.74 & 4.59 \\
\hline
\end{tabular}

The interpretations were given based on the raw score and mean value, Based on the scoring they may be categorised as Very High Scorer, High Scorer, Average Scorer, Low Scorer and Very low Scorer.

\section{Utility of the Life Skills Assessment Scale}

- $\quad$ This LSAS can be used for self assessment on the life skills

- $\quad$ Training need analysis can be conducted with the help of LSAS to identify the core area of training needs.

- $\quad$ The LSAS clearly measures the level of Life Skills so that the sealing effect of the training programme can be identified since the reliability is very high (Split half .82). This effect would be evident on training the low scorers who have skill deficits, in other words, the low scorers after effective life skills training; 
the post training score will show significant improvement. The moderate or high scores need not necessarily show a significant improvement after the training. Hence it becomes essential to plan and structure the training highly effective to bring a shift in the behaviour of the respondents.

- This LSAS can be an effective tool to structure the training programme to implement tailored model for the specific group as well as it help the trainer to evaluate the lacuna in the training, so this becomes both detective as well as reflective tool for the professional trainers.

- $\quad$ This could be an effective tool to measure the effectiveness of the life skills training

- The tool could be used for educational, training, diagnostic, selection, recruitment and employment and self developmental purposes

\section{References:}

[1] Bandura, A. (1977a). "Self-efficacy: Toward a Unifying Theory of Behavior Change." Psychological Review. 84 191-215.

[2] Bandura, A. (1977b). Social Learning Theory. Englewood Cliffs, NJ: Prentice-Hall.

[3] Basen-Engquist K., et al (1994). "The Effect of Two Types of Teacher Training on Implementation of Smart Choices: A TobaccoPrevention Curriculum.” Journal of School Health. October. 64(8): 334-339.

[4] Beyth-Marom, R.; Fischhoff, B.; Jacobs, M.; and Furby, L. (1989). Teaching Decision-Making to Adolescents: A Critical Review.Carnegie Corporation of New York.

[5] Bierman, K. and Montminy, K. (1993). "Developmental Issues in Social-skills Assessment and Intervention with Children and Adolescents." Behavioral Modification. 17:5 (July) 229-254.

[6] Bosworth, K. and Sailes, J. (1993). "Content and Teaching Strategies in 10 Selected Drug Abuse Prevention Curricula." Journal of School Health. 63(6): 247-446

[7] Botvin, G.; Baker, E.; Dusenbury, L.; Botvin, E.; and Diaz, T. (1995). "Long-term Follow-up Results of a Randomized Drug Abuse Prevention Trial in a White Middle-class Population.” JAMA (April 12). 273, (14) 1106-1112.

[8] Botvin, G.J.; Schinke, S.P.; Epstein, J.A.; and Diaz, T. (1995). "The Effectiveness of Culturally Focused and Generic Skills Training Approaches to Alcohol and Drug Abuse Prevention Among Minority Youth: Two-Year Follow-up Results.” Psychology of Addictive Behaviors. 9, 183-194.

[9] Botvin, G.J.; Schinke, S.P.; Epstein, J.A.; and Diaz, T. (1994). "The Effectiveness of Culturally Focused and Generic SkillsTraining Approaches to Alcohol and Drug Abuse Prevention Among Minority Youth.” Psychology of Addictive Behaviors. 8, 116-127.

[10] Botvin, G.; Epstein, J.; Schinke, S.; and Diaz, T. (1994). "Predictors of Cigarette Smoking Among Inner-city Minority Youth." Developmental and Behavioral Pediatrics. (April) 15(2) 67-73.

[11] Botvin, G.J.; Dusenbury, L.; Baker, E.; James-Ortiz, S.; Botvin, E.M.; and Kerner, J. (1992). "Smoking Prevention Among Urban Minority Youth: Assessing Effects on Outcome and Mediating Variables.” Health Psychology. 11, (5), $290-299$.

[12] Botvin, G.J.; Baker, E.; Dusenbury, L.; and Botvin, E.M. (1990). "Preventing Adolescent Drug Abuse through a Multimodal Cognitive-Behavioral Approach: Results of a Three-Year Study.” Journal of Consulting and Clinical Psychology. 58 (4), $437-446$.

[13] Botvin, G.J.; Baker E.; Filazzola, A.; and Botvin, E.M. (1990). "A Cognitive-Behavioral Approach to Substance Abuse Prevention: A One-year Follow-up." Addictive Behaviors. 15, 47-63.

[14] Botvin, G.J.; Dusenbury, L.; Baker, E.; James-Ortiz, S.; and Kerner, J. (1989). “A Skills Training Approach to Smoking Prevention Among Hispanic Youth.” Journal of Behavioral Medicine. 12, 279-296.

[15] Botvin, G.J. (1986). "Substance Abuse Prevention Research Recent Developments and Future Directions." Journal of SchoolHealth. November. 56(9). 369-373.

[16] Botvin, G.J.; Baker, E.; Botvin, E.M.; Filazzola, A.D.; and Millman, R.B. (1984). "Alcohol Abuse Prevention through the Development of Personal and Social Competence: A Pilot Study.” Journal of Studies on Alcohol. 45, 550-552.

[17] Botvin, G.J.; Eng, A.; and Williams, C.L. (1980). "Preventing the Onset of Cigarette Smoking through Life Skills Training." Preventative Medicine. 9, 135-143.

[18] Caplan, M.; Bennetto, L.; and Weissberg, R. (1991). "The Role of Interpersonal Context in the Assessment of Social ProblemSolving Skills.” Journal of Applied and Developmental Psychology. 12 103-114.

[19] Coie, J. (1985). "Fitting Social Skills Intervention to the Target Group.” In Schneider, B.; Rubin, K.; and Ledingham, J. (Eds.). Children's Peer Relations: Issues in Assessment and Interventions. New York: Springer-Verlag.

[20] Coie, J. and Koeppl, G. (1990). “Adapting interventions to the problem of aggressive and disruptive rejected children.” In Asher,S. and Coie, J. (Eds.). Peer Rejection in Childhood. New York: Cambridge University Press.

[21] Daniel, H. (Ed.) (1996). An Introduction to Vygotsky. Routledge. New York, NY.

[22] Deffenbacher, J.; Lynch, R.; Oetting, E.; and Kemper, C. (1996). “Anger Reduction in Early Adolescence.” Journal of Counseling Psychology. 41(2) 149-157.

[23] Deffenbacher, J.; Oetting, E.; Huff, M.; and Thwaites, G. (1995). "Fifteen-month Follow-up of Social Skills and CognitiveRelaxation Approaches to General Anger Reduction." Journal of Counseling Psychology. 42(3) 400-405.

[24] Dodge, K.; Pettit, G.; McClaskey, C.; and Brown, M. (1986). "Social Competence in Children." Monographs of the Society for Research in Child Development. 51.

[25] Donaldson, S.; Graham, W.; and Hanson, W. (1994). "Testing the Generalizability of Intervening Mechanisms Theories: Understanding the Effects of Adolescent Drug Use Prevention Interventions.” Behavioral Medicine. 17(2):195-216.

[26] Dubey.L.N.and Archna, D. (1971). Manual for Swentence Completion Test.Agra,National Psychological Corporaton.

[27] Dusenbury, L. and Falco, M. (1995). "Eleven Components of Effective Drug Abuse Prevention Curricula." Journal of School Health. December. 65(10): 420-425.

[28] Eccles, J. (1999). "The Development of Children Ages 6 to 14." The Future of Children. Fall. 9(2). 30-44.

[29] Elias, M.; Gara, M.; Schulyer, T.; Brandon-Muller, L.; and Sayette, M. (1991). "The Promotion of Social Competence." American Journal of Orthopsychiatry. July. 6(13). 409-417.

[30] Elias, M. and Kress, J. (1994). "Social Decision-Making and Life Skills Development: A Critical Thinking Approach to Health Promotion in Middle School." Journal of School Health. 64(2): February. 62-66.

[31] Elias, M. and Branden, L. (1988). "Primary Prevention of Behavioral and Emotional problems in School-Aged Populations." School Psychology Review. 17(4) 581-592.

[32] Elliott, S. and Gresham, F. (1993). "Social Skills Interventions for Children.” Behavior Modification. 17:3, July. $287-313$.

[33] Englander-Goldern, P.; Jackson, J.; Crane, K.; Schwarkopf, A.; and Lyle, P. (1989). "Communication Skills and Self-Esteem 
inPrevention of Destructive Behaviors.” Adolescence. 14 481-501.

[34] Evans, R. (1998). “A Historical Perspective on Effective Prevention.” In Bukoski, W. and

[35] Evans, R. et al (1978). "Deterring the Onset of Smoking in Children: Knowledge of Immediate Physiological Effects and Coping With Peer Pressure, Media Pressure and Parent Modeling." Journal of Applied Social Psychology. 8.

[36] Evans, R.I. (1976). "Smoking in Children: Developing a Social Psychological Strategy of Deterrence." Preventive Medicine. 5.

[37] Jessor, R. (1993). "Successful Adolescent Development Among Youth in High-risk Settings." American Psychologist. February. 48:2 117-126.

[38] Jessor, R. (1992). "Risk Behavior in Adolescence: A Psychosocial Framework for Understanding and Action." In: Rogers, D andGinzburg, E. (Eds.), Adolescents at Risk: Medical and Social Perspectives. Boulder, CO: Westview Press.

[39] Jessor, R. and Jessor, S. (1977). Problem Behavior and Psychosocial Development. Orlando, FL.

[40] Jessor, R.; Donovan, J.; and Costa, F. (1991). Beyond Adolescence. New York: Cambridge University Press.

[41] Health. New York: John Wiley and Sons.

[42] Luthar, S. and Zigler, E. (1991). "Vulnerability and Competence: A Review of Research on Resilience in Childhood." American Journal of Orthopsychiatry. 61(1) January 6-22.

[43] Luthar, S. and Zigler, E. (1992). "Intelligence and Social Competence Among High-risk Adolescents." Development and Psychopathology. (4), 287-299.

[44] McGuire, W.J. (1968). “The Nature of Attitudes and Attitude Change.” In: Lindzey, G. and Aronson, E. (Eds.), Handbook of Social Psychology. Reading, MA: Addison-Wesley.

[45] McGuire, W. (1964). "Inducing Resistance to Persuasion: Some Contemporary Approaches." In: Berkowitz, L. (Ed.), Advances in Experiential Social Psychology. New York: Academic Press.

[46] Meyer, A. and Farrell, A. (1998). "Social Skills Training to Promote Resilience in Urban Sixth Grade Students: One Product of an Action Research Strategy to Prevent Youth Violence in High-Risk Environments." Education and Treatment of Children.

[47] Mize, J. and Ladd, G. (1990). "A Cognitive-Social Learning Approach to Social Skills Training with Low-status Preschool Children." Developmental Psychology. 26(3) 388-397.

[48] Pershad.D and Wig.N.N. (1971). P.G.I. Memory Scale,Agra, National Psychological Corporation.

[49] Ross, J. et al (1991). "Teenage Health Teaching Modules: Impact of Teacher Training on Implementation and Student Outcomes." Journal of School Health. 61(1) 31-38.

[50] Rutter, M. (1987). "Psychosocial Resilience and Protective Mechanisms." American Journal of Orthopsychiatry. 57:3 (July) 316331.

[51] Schinke, S.; Blythe, B.; and Gilchrest, L.D. (1981). "Cognitive-Behavioral Prevention of Adolescent Pregnancy." Journal of Counseling Psychology. 28 451-454.

[52] Schneider, B. and Bryne, B. (1985). Children's social skills: A meta-analysis. In: Schneider, B.; Rubin, K.; and Ledingham, J. (Eds.), Children's Peer Relations: Issues in Assessment and Intervention. New York: Springer-Verlag.

[53] Shure and Spivack (1988). "Interpersonal Cognitive Problem-Solving." In Price, R.; Cowen, E.; Lorion, R.; and RamosMcKay(Eds), Fourteen Ounces of Prevention: A Casebook for Practitioners, pp. 69-82. American Psychological Association, Washington, DC.

[54] Shure and Spivack (1982). "Interpersonal Problem-Solving in Young Children: A Cognitive Approach to Prevention." American Journal of Community Psychology. 10 (3).

[55] Shure and Spivack (1980). "Interpersonal Problem Solving as a Mediator of Behavioral Adjustment in Preschool and Kindergarten Children.” Journal of Applied Developmental Psychology. (1): 29-44.

[56] Shure and Spivack (1979). "Interpersonal Cognitive Problem Solving and Primary Prevention: Programming for Preschool and Kindergarten Children." Journal of Clinical Child Psychology. Summer.

[57] Slaby, R. and Guerra, N. (1988). "Cognitive Mediators of Aggression in Adolescent Offenders." Developmental Psychology. 24, 580-588.

[58] Steinberg, L. (2000). The Family at Adolescence: Transition and Transformation. Journal of Adolescent Health. 27:170-178.

[59] Sullivan Palincsar, A. (1998). "Social Constructivist Perspectives on Teaching and Learning." Annual Review of Psychology.

[60] Tappe, M.; Galer-Unti, R.; and Bailey, K. (1995). "Long-Term Implementation of the Teenage Health Teaching Modules by Trained Teachers: A Case Study.” Journal of School Health. December. 65(10): 411-415.

[61] "The Science of Prevention: A Conceptual Framework and Some Directions for a National Research Program." American Psychologist. 48, 1013-1022.

[62] Thompson, K.; Bundy, K.; and Wolfe, W. (1996). "Social Skills Training for Young Adolescents: Cognitive and Performance Components." Adolescence. Fall. 31(123).

[63] Tobler, N. (1992). "Drug Prevention Programs Can Work: Research Findings.” Journal of Addictive Diseases. 11(3).

[64] Tobler, N. and Stratton, H. (1997). "Effectiveness of School-based Drug Prevention Programs: A Meta-Analysis of the Research." Journal of Primary Prevention. 18(1):71-128.

[65] United Nations Development Programme (UNDP) (1994). Human Development Report 1994. New York: Oxford University Press.

[66] United Nations Children's Fund (UNICEF) (1997a). Adolescent Childbearing the Latin America and the Caribbean. New York: UNICEF.

[67] United Nations Children's Fund (UNICEF) (1997b). Youth Health—For a Change: A UNICEF Notebook on Programming for Young People's Health and Development. New York: UNICEF.

[68] United States Census Bureau (2000). International Programs Center. International Data Base. (IDB)

[69] Vohra.S. (1994). Handbook for DBDA (Revised),New Delhi, Psy Com Services.

[70] Westen, D. (1996). Psychology: Mind, Brain, and Culture. John Wiley and Sons, Inc. Harvard University.

[71] Wodarski, J.S. and Feit, M.D. (1997). "Adolescent Preventive Health: A Social and Life Group Skills Paradigm.” Family Therapy. 24 (3). 191-208.

[72] Wolman, B. (1968). Historical Roots of Contemporary Psychology. Harper and Row Publishers, New York

[73] World Bank (1999). Educational Change in Latin America and the Caribbean. Social and Human Development. Washington,DC. 